\title{
Exploring Students' Group Work Needs in the Context of Internationalisation Using a Creative Visual Method
}

\author{
Andrew Cox (Corresponding author) \\ Information School, University of Sheffield \\ Sheffield, S1 4DP, UK
}

Tel: 44-(0)114-222-6347Ｅ-mail: a.m.cox@sheffield.ac.uk

Prue Chiles \& Leo Care

School of Architecture, University of Sheffield

Sheffield S10 2TN, UK

Tel: 44-(0)114-222-0399_E-mail: p.chiles@sheffield.ac.uk, 1.care@sheffield.ac.uk

\author{
Received: May 8, 2012 \\ Accepted: May 30, 2012 \\ Online Published: June 7, 2012 \\ doi:10.5430/ijhe.v1n2p21 \\ URL: http://dx.doi.org/10.5430/ijhe.v1n2p21
}

\begin{abstract}
While UK universities see group work as essential to building higher order intellectual and team skills, many international students are unfamiliar with this way of studying. Group work is also a focus of home students' concerns. Cultural differences in the interpretation of space for learning or how spatial issues affect group work processes has not been much explored in the internationalisation literature. The research described in this paper used data based on Chinese and home students making models of a good group work space. The data showed no marked cultural differences in visual taste. However, Chinese students were more concerned with the emotion of group work while home students were task focussed. All designs opted for a neutral office style design, rather than celebrating diversity. The paper supports the value of creative visual methods in exploring difficult to articulate topics, as part of a package of qualitative research methods.
\end{abstract}

Keywords: Internationalisation, Group work, Chinese students, Space

\section{Introduction}

Within certain ways of thinking about internationalisation (Morey, 2000), visiting students are seen primarily as having a deficit and needing to adjust to local educational practice. In this perspective, because international students often lack experience of group work and given the importance of it in Higher Education (HE) practice, one of the key problems is their gaining an understanding of how to work in groups. In more responsive or transformative perspectives of internationalisation, there is a recognition of the potential international students bring to change local practice, at a more or less profound level. In group work this might mean actively discussing with students how they conceive group work and renegotiating what group work is about (Skelton, 2005). Increasingly in the internationalisation-at-home literature it is recognised that United Kingdom (UK) born students' responses are crucial, for their indifference or feeling of being "swamped" is a key aspect of how international students are received (Dunne 2009, Peacock and Harrison, 2009, 2010). Again, group work is a key problem area because students seem to want to work with people like themselves and have pragmatic fears about the effect of working in mixed groups on their marks (Peacock and Harrison, 2009). The potential benefit to UK students in learning greater cultural agility through group work with international students is seemingly a weaker motive than the attractions of working with friends and reducing risk.

Chinese students are the largest single group of international students in the UK (UKCISA, 2011). Chinese students often seem to become enclaved, partly because there are a large number of them on campus (Brown, 2009a). The authors' own anecdotal observations of Chinese student behaviour in the classroom suggests that they often sit separately as a group and tend to work separately. The personal motive for this research was to discover more about how this came about and identify what could be done to break down the barriers. The approach taken is to focus on space. Directly in relation to internationalisation little has been written about space as such, yet different aesthetics or 
expectations of the use of space could be a specific issue in itself. Examining different experiences of space might also be a good indirect way of examining cultural mixing since use of space reflects largely unconscious assumptions about learning and equally the given organisation of space directly shapes learning as a concrete set of embodied practices. Thus examining spatial aspects of experience may be one way into the multi-faceted problems around group work.

In this context, the research described in this paper undertook to begin to address the following questions:

- Are there different cultural aesthetics or expectations among UK and Chinese students around learning space that could impact on group work (e.g. attitudes to privacy or expectations about building design)?

- What new insights into the factors shaping Chinese/UK students interactions in group work are revealed by examining perceptions of space?

The paper further examines the value of creative visual methods in examining these questions.

The article is laid out as follows. The paper first reviews the literature about the integration of Chinese students and international students, and in particular the conclusions of previous studies of group work. It then looks at some of the literature on the spatial aspects of learning. The creative visual method used in the research is then explained. The findings explore the similarities and subtle differences between the attitudes revealed in the data. A discussion considers these findings in relation to previous knowledge and also reflects on the merits of the data collection method employed.

\section{Internationalisation and group work}

Chinese culture is complex and there is a risk of thinking in stereotypes that construct Chinese culture as unitary (Clark and Gieve, 2006) and Other. Thus some literature constructs a stark contrast between "collectivist" Chinese and "individualist" Western cultures (Clark and Gieve, 2006). "Confucian culture" is said to be different from western thinking, specifically generating different expectations about learning. Some argue that this is just a myth (Tani, 2005) and certainly one can draw too stark a contrast, forgetting the increasing diversity in age and background of UK students themselves (Ippolito, 2007). Yet there is some substance to cultural difference. Specifically, certain aspects of British student culture create a division: among these are the drinking culture, dress codes (Philo, 2007) and party culture (Tian and Lowe, 2009) as well as more general cookery practices and health care (Edwards and Ran, 2006). While some experiences of coming to University are common to all students, e.g. experiences of loneliness or identity issues, others, such as culture shock are not (Zhou and Todman, 2009). So there is a common ground in a common problem among all international students, but it is not shared with UK students. Other demographic differences between Chinese and UK students can have an effect on interaction: e.g. differences in age or where students live. For example, if UK students are working or living at home, simple practical issues will affect interaction with international students, who might be living on campus and studying full time.

Specifically, past learning experiences are also likely to be different. Like many international students, Chinese students will find the meaning of plagiarism, marking systems and expected modes of study and class room interaction to be different from their previous experience (Edwards and Ran, 2006). They may well be unfamiliar with the UK emphasis on discussion and group work. There is some evidence that both international and UK students prefer conational groups (e.g. Volet and Ang, 1998, Brown, 2009a, Dunne, 2009), because of

- "Cultural-emotional connectedness" (Volet and Ang, 1998, p.10), feelings of having common ground in common experience.

- Language. Language is a barrier for international students because it is tiring to work in a foreign language, their mistakes are a cause of anxiety and feelings of shame and because their own language is very important to expressing their identity (Brown, 2009a). Some UK students say that it feels that they cannot express themselves fully when talking to non-native speakers (Dunne, 2009).

- $\quad$ Pragmatism. UK students see working with international students as risking achieving lower marks (Peacock and Harrison, 2009). Academic and time pressure could reduce the possibilities of reaching cohesion (Ippolito, 2007).

- Negative stereotypes. Turner (2009) found that negative stereotypes among UK students focussed on international students language skills and ability to operate in groups. In her class the need to work as a group became a punitive discourse, that "privileged emotionally restrained, task focussed, competitive behaviours"(2009, p.252) rather than a supportive environment. This reflects the unchecked operation of asymmetric power relations 
between students arising from differences in language competence (Tian and Lowe, 2009). Tian and Lowe (2009) found active exclusion of Chinese students by UK students, but it seems that international students also sometimes assume that UK students do not want to work with them (Volet and Ang, 1998).

Peacock and Harrison (2009) conclude that although UK students were mindful of language issues and did not wish to stereotype others, they did exhibit "passive xenophobia". Chinese students were seen as particularly distant. Dunne (2009) concludes that the experience of UK students working with international students is not "necessarily negative but more demanding" and Peacock and Harrison (2009) argue that UK students tend to go for what is easy which translates to working with co-nationals: those that they perceive to be like themselves.

"Completion of collaborative learning activities in culturally diverse small groups is a highly complex, socially and emotionally demanding experience" (Kimmel and Volet, 2010, p.3)

This quote encapsulates the challenge and risk that might be perceived in multi-national group work among students.

On the more positive side, while negative views strengthen where non diverse groups are the norm (Kimmel and Volet, 2010), attitudes do seem to change through contact (Volet and Ang, 1998). There is also evidence that cultural diversity can enhance performance (Summers and Volet, 2008) but perhaps only in long term collaborations (Gibbs, 2009). Benefits (especially for UK students) through gaining skills in inter-cultural understanding and communication, are ethically and socially highly desirable (Leask, 2004) and also seen as highly desirable within institutional rhetoric, e.g. within the employability agenda. Of course, this is primarily about the potential benefit to UK students; Chinese students are already getting a very powerful inter-cultural encounter from their whole experience of being abroad, a learning experience which may greatly outweigh anything they gain from the formal learning process (Brown, 2008; Simpson, Sturges and Weight; 2009, Gu, 2009). Whereas international students come with an expectation to have to learn to adapt to a new culture, the compulsion to change or even be transformed is less obvious for students who remain in their own country.

A finding that only $15 \%$ of Chinese students had a UK friend (UKOSA, 2004) suggests that UK HE is not being very successful in integration. There is a tendency not to actively manage integration in the classroom (Peacock and Harrison, 2009); too often teachers are simply "wishing and hoping" (Leask \& Carroll, 2011). Though the literature contains a lot of useful thinking about how to scaffold multinational group work (e.g. Carroll, 2005; Skelton, 2005; Leask and Carroll, 2011), our pedagogic commitment to group work must be linked to an understanding of how international integration can be achieved. Active investigation of how students think and operate can specifically help demystify Chinese culture.

\section{The spatial turn}

Usher suggests that in modernist thinking time and history are privileged over space (Usher 2002:41), and this seems to be reflected in educational theory. For although metaphors of space are very powerful in educational discourse (Sagan, 2008), until recently the nature of the relationship between space and learning has not been greatly studied or theorised. Echoing a call for a spatial turn in the social sciences generally (e.g. in sociology (Baldry, 1999) and organization studies (Taylor and Spicer, 2008)) a number of authors have called for space to be more fully theorized in the study of education (e.g. McGregor, 2003; Edwards and Usher, 2003). The work of Lefebevre, Soja and Massey, in particular, are becoming increasingly influential in such work. Here space in education ceases to be seen as pre-given, as a bounded, discrete entity, or a backdrop for action, but rather is recognized as itself the outcome of an ongoing, contested and productive process, in which social and material factors, and local and global forces operate. The relatively enduring patterns in spatiality, rather than reflecting necessary conditions or being essential or innocent, are to be seen as reflecting a pattern created by power relations (McGregor, 2004) yet are constantly remade and potentially capable, therefore, of being reframed. The approach also recognises that there are multiple experiences and narratives of any space (Thomson, 2007).

After a period when writers have speculated about the physical university disappearing replaced by virtual learning environments, and without discounting the impact of technology on space, there has been a revival of interest in physical space and built environment in universities (Temple, 2007) immediately tied to a wave of new building, itself driven by competition for students. The 1990s and 2000s saw an increasing investment in campus infrastructure and much exciting experimentation with new learning space design. The context for this change was a move to student centred learning notions in the 1990s, driven by shifts in the demand from the economy for more skills of "critical thought, clarity of expression and complex decision making" (Marmot Associates, 2006, p. 20). New spatial ideas recognise the value of learning through reflection, doing and informal conversation (Marmot Associates, 2006, p. 4). Chism proposes the requirements for active learning as "flexibility, comfort, sensory stimulation, technology 
support and decentredness" (2006, p.2.6-7).

There is a little empirical research on HE learning spaces. Space shapes pedagogic choices and morale in learning (Jessop et al., forthcoming). The strength of students' affective response to learning space can be surprising to educators (Cox 2011). Aesthetics are also important. In a study of student and staff views of lecture theatres, Douglas and Gifford (2001) found that staff and students agreed in evaluating "sociopetal seating, a view of the outdoors and comfortable seats" as the most desirable features of learning spaces. Interestingly, some of these considerations recur in studies of primary and secondary school children, for which there is a greater body of research (e.g. Burke \& Grovesnor, 2003; Clark, 2010). For example, in a number of studies of very young children using participative methods, Ghaziani (2010) found windows were a focus of concern, because of a desire to see out and have a connection to the outside. They preferred to have windows of different sizes and shapes. Children were also concerned with the quality of artificial lighting. Burke \& Grovesnor (2003) argue that schools should be "beautiful, comfortable, safe and inclusive" (2003, p.17). Clark (2010) also found school children concerned with lights and lighting and with colour and beauty, as well as other aspects such as privacy and legibility.

These pieces of research were often grounded in the current school and satisfaction with it. Where school children's imaginations are strongly engaged more radical views seem to emerge. Australian studies summarized by Bland (2010), and confirmed by his own investigation, suggest that school children believe that "learning should be fun and that learning environments should be eco-friendly and imaginative. They also emphasised colour and excitement." Children often wanted to take learning out of the classroom in places where hands on learning was possible, reflecting as Bland observes the ideas of many educational theorists, such as Dewey and Illich. That outdoors is important to school children was also one of Clark's (2010) findings.

Turning back to the relatively less researched context for this study, Higher Education, much discussion about how campus design should be changed has been around the notions of the information commons and learning commons. During the late 1990s a concept of the information commons emerged in the USA (Spencer, 2006). Information commons are often centrally located, campus showpieces, especially for the implementation of the most advanced technology. These types of space are "wildly popular" with students (Spencer, 2006, p.242), yet they have not been received without criticism. Jamieson (2009) notes the irony of centralising informal learning, in a context of also talking about students needing to take control over their own learning. This could be an example of a visual disciplinary process, in which informality is itself made visible for regulation. Spicer and Hancock (2008) see information commons redesigns as a deliberate remoulding of the visual aesthetics of the library to reference the imagery and use of space in business, and as having continuity with adjustments of the public sector to neo-liberal, anti-statist ideology. Bennett (2005) advocates the importance of embracing a further move from information commons to learning commons, from a focus on an "effective service space" to design "one that encourages students to devote more time to study". Understanding the needs of learning implies "providing choices of place", "permitting territorial claims" and yet "fostering a sense of community among students" (Bennett, 2005). He refers to this as the "domestication" of public spaces of libraries. There is an affinity between Bennett's stress on the domestication of space and Sagan's (2008) suggestions about designing spaces to address the need to create an emotionally stable and secure transitional space as necessary for creative learning. Her suggestions are made within the specific context of art and the experience of those with a troubled history of education, but if it is accepted that much learning, especially that which challenges our core values through inter-cultural encounters, is inherently discomforting (Boler and Zemblyas, 2003) it may also be logical to think of needing to construct safe spaces for other forms of learning too. Clearly, in the context of the scale of the modern university and drivers for efficient use of space, doing this is problematic, however.

Thus there is a growing interest in spatial aspects of learning in higher education. Yet there is little literature that specifically deals with international students' experience of campus space or examines how spatial aspects shape learning experiences, such as in group work. This paper makes a small contribution to beginning to fill this gap.

\section{Method}

\subsection{The research process}

The data discussed in this paper was gathered through a creative visual method, borrowed from community orientated architectural design. After a standard focus group discussing group work attitudes, participants were given 45 minutes to construct a model of a design that would be effective for organizing group work. As a starting point each was given pre-prepared cardboard framework, rather like a small stage set, with a base of $16 \mathrm{~mm}$ by $13 \mathrm{~mm}$ and a height of $9 \mathrm{~mm}$. They were also supplied with images of types of space (actual university spaces, traditional looking learning spaces and more imaginative ones), colour paper, knives to cut up the material and coloured pens. A 
recording was then made of each participant verbally explaining their design to the group, supplemented by a written reflection consisting of 1) a description of their model and 2) an explanation of "why you think the design is good for working in a multi-national group". Thus the data generated in the research was the models and verbal and written descriptions of them by their creators, i.e. the end products of the process.

\subsection{Visual methods}

Such creative and visual methods have been quite widely used in the study of children's views of their school including the classroom, sometimes as part of a participatory design process. Methods include poems, photography, drawing, map making and children led tours; with researchers usually using multiple methods to increase validity (Ghaziani, 2010) and richness, as in the Mosaic approach (Clark, 2010). One of the strengths of the approach is getting away from functional efficiency which is often at the forefront of design considerations.

The argument for the benefits of a "creative, visual method" as set out in general terms by Bragg (2011) seemed convincing for the current research. Firstly, the exercise itself fitted the research questions: It is easier to explore ideas about three dimensional space by actually making a model than just talking. Secondly, since the method was not primarily verbal, its use addressed the inequality in English language skills among participants. The approach prevented the discussion being dominated by UK students with their superior command of the lingua franca. This was a significant argument given the theme of the study. As in all creative methods, other skill issues were relevant. Thus the ability of participants to express their understanding was linked to skill in manipulating the materials provided and certainly worries about their own skill in doing this and having to show their work to others could inhibit participants' concentration on the design process. But the value in equalising the power derived from language skills was seen to outweigh such problems. Model making could be seen as escaping the potential negativity of a verbal discussion that would be likely to repeat given discourses that effectively reproduce the problem. Ethical research should itself not reproduce the problem it is investigating. The method could also be seen to recognise the increasing cultural importance of visual expression, if one accepts the claim that contemporary culture is a visual culture and if that is understood to imply greater visual literacy (Bragg, 2011).

It has been suggested that there are strong emotions among UK students about group work, but also a taboo about talking about it for fear of accusations of xenophobia or even racism (Peacock and Harrison, 2009). Thus a third strength of the approach for this study was the method's ability to explore emotional and controversial aspects of participants' views of space. Getting participants in research to articulate aesthetic and symbolic experiences of the organisation, or organisational space as such, is hard (Taylor 2002). Taylor identifies the cause of such "aesthetic muteness" in the way that talking about feeling is a less legitimate discourse in many organizations because it undermines instrumental cultures in that it "complexifies and distracts" (2002, p. 835). Arguably, this holds true for educational organisations as for others.

Nevertheless, the current enthusiasm for visual/creative methods (Prosser and Loxley, 2008) is not without its critics (e.g. Buckingham, 2010). From the point of view of the constructivist view of knowledge, the products of such an exercise cannot be seen as simple reflections of the mental categories of participants. Certainly, the creative process is itself one of representation and is likely to be understood by participants via pre-existing genres of communication, with their own rules. This implies identifying the genre participants thought was relevant to the model making, as part of the process of analysis. The participating students' own interpretations of their models that the researchers gathered is useful in this regard.

\subsection{Participants}

After ethical clearance through the university ethics process, Chinese and UK participants were recruited primarily from the Information School, with a smaller number from Architecture, at the University of Sheffield. In reporting the results the authors have focussed on the Information School participants, partly because there were more of them and partly because it was felt that their contributions were less shaped by professional knowledge and expectations. 10 models from 4 UK and 6 Chinese students are analysed below. The research should be seen as exploratory, seeking partly to validate the method, partly to produce some initial findings. Since the participants were just one small group of students in one cohort in one department in one university at one time inevitably the substantive findings must be treated with considerable caution. It was noticeable for example that designs were heavily influenced by local experience, and specifically the existence at Sheffield of an information commons building (Lewis, 2010). One would expect somewhat different results in the context of a teaching driven university. Even the timing (spring 2010) relative to wider social debates about the value of multiculturalism and migration, could have influenced the findings. 


\section{Findings}

Looking at the workshop participants' designs, strong cultural differences in the view of space were not apparent. Almost all the designs had a preoccupation with maximising the amount of natural light in the room e.g. using transparent walls, large windows or skylights to let in more light. Many of the designs also stressed the need for aesthetically pleasing spaces. As well as reflecting a desire for pleasing and comfortable spaces, these preferences could be seen as linked to status concerns, for according to Baldry (1999) in organizations generally, space is symbolic of status, so that the amount of space given to an individual and its quality are interpreted as indicators of status.

\subsection{Anxiety control and task focus}

If there was a difference between UK and Chinese students, it was perhaps in the Chinese students' stress on simplicity, seemingly as a response to concerns about anxiety, distraction and energy levels. Several introduced their model by talking about it as a "simple" design, partly, perhaps, as a self deprecating response to some of the more ambitious models being presented from architecture students. However, they were also, it seemed, genuinely seeking a spare design. Several talked about actively choosing to reduce the amount of furniture. In some sort of way this seemed to be linked to anxiety and distraction. One participant (I1) wrote:

"My ideas come about making people peaceful and calm[ed] down especially for groups of four people [or] above. This is because when more students get together, they tend to talk [about] something else rather than their work. Therefore, simpl[e] colours and furniture are used, which may cause less distractions."

Anxiety and distraction seem strongly interlinked in this particular formulation. Simple colours were for her black, silver etc, which are also chosen because they have less specific cultural associations.

Figure 1. I1's design based on "simple" colours and few distractions

Other participants explicitly mentioned relaxation, often by taking food and drink, and energy levels were a concern. A second Chinese student (I2) wrote in her reflection:

"It is a design for small group discussion. The floor is designed blue [...] just like the sky. This kind of colour can make students feel comfortable and relax[ed]. There are some soft mats on the floor. The students can sit on the soft mats which make them feel comfortable. There is a large table which people can put laptops or discussion materials on [... or] food or water [...] there is a special chair which looks like a circle. It provides a magic environment for the students. A simple chair is preferred as well, when the students feel a little tired they can sit down on the simple chair in turns. [...] Last but not least, from different types of windows, the students can see the beautiful view."

Figure 2. I2's design with sky blue floor, soft mats and a special chair

The preoccupation with the anxiety and stress of group work was less noticeable in UK students' talk about designs. UK students' designs seemed to focus more on functions and the challenge of task complexity. They had more complex spaces for multiple aspects of group work or starkly differentiated formal and informal spaces. By including multiple types of space there was a way to contain distraction: to allow people to do individual things but remain within the group work process. One UK student's design (I3) elaborated on this issue.

"The idea here was [...] you just had different sorts of spaces for different points of time of group work. So you might obviously need to get around a table. It might be to break out or you just go and relax. [...] If one was doing a long session where you were getting together and then going off individually. [...] Or people just need to get in touch with something they have to get on with but being in a space that let's you just get together again." [verbal comment in plenary]

Another UK student's (I4) design demarcated space for formal work and informal work.

"The room on one side has a table, chair (black and white) which is sleek. There is a computer on the table as well as wifi internet in the whole room. On the other side there [are] some steps where you go into a booth which has lots of beanbags/cushions for chilling out and informal learning such as discussion this half is extremely colourful with bright green, orange etc.” [text reflection]

Figure 3. I4's design with two walls that are windows and one translucent wall.

UK students' designs seemed to conceive a bookable (temporarily ownable) space that contained some group task complexity. Chinese students' designs were more unitary or where the space had multiple elements there was a focus on making room for simple relaxation or consuming food, rather than, as in the designs described above to undertake 
some of the more informal discursive parts of the task. This must be treated as a tentative analysis, partly because of the small amount of data. If the differences actually exist, they can be understood not as cultural difference, but simply as reflecting differences between people who are confident in a familiar context and others who have a pervasive sense of being in an alien place.

\subsection{The visual}

Almost all the designs had a preoccupation with maximizing the amount of natural light in the room e.g. using transparent walls, large windows or skylights to get in more light. Many of the designs also stressed the need for aesthetically pleasing spaces, with a view of the natural world (or in one case over the city) or having art to decorate the room. Yet there was also a concern, mostly among Chinese students, with views being distracting. As well as wishing to have a good view out, there was a marked desire to control visibility from outside: specifically to be able to show that one was occupying a space, yet not be identifiable, to both avoid interruption from friends and to maintain privacy for the work of the group. One way this was accomplished was having opaque glass panels. The concern with privacy was perhaps more evident among the UK students. Interestingly, none of the designs made reference to access to academic or support staff (e.g. librarians or IT support) or indeed expressed concerns over surveillance by such staff (the concern was visibility to other students). As well as reflecting a desire for pleasing and comfortable spaces, these preferences could be seen as linked to status concerns, within Baldry's (1999) analysis. A good view is a status marker.

The designs also showed a preoccupation with colour. But there was marked divergence about preferred colours: one used "natural" greens, another the blue of the sky for the floor and in a third bright colours were used to define less formal space. One student elaborated a pseudo-scientific discourse around the effect of colour on energy level and calmness; while another (already quoted as I1) was concerned with avoiding culturally significant colours in her design. I1 saw black and silver as culturally neutral, whereas I4 chose black and white as indicative of formality.

\subsection{Conservative designs?}

When given the chance to design learning spaces children often propose outdoors spaces, implying a desire to de-institutionalise learning and learn by doing (Bland, 2010). It is interesting that none of the students proposed a more natural, open space or even introduced plants into their designs (rather nature was a view or the subject of a painting). They produced designs that looked like formal learning, even office space; rectilinear spaces with chairs and computers. In this respect they could perhaps be seen as rather unadventurous designs. They were all quite clearly bounded spaces, indeed a concern to mark off territory was a recurrent concern. This could be partly because of how the activity was set up with a box shape as a starting point, though they were urged to break out of this if they wanted. We could tentatively conclude from the formality of the designs that all the students were socialised into the notion of a relatively traditional learning environment. This supports Jamieson's (2009) view that the success of institutions' information / learning commons type buildings shapes ideas of the informal. What informality means has begun to be defined for students, more radical thoughts ruled out.

It also seemed that when thinking about designing for groups, especially diverse groups, the participants were choosing to leave out personally and culturally significant objects, and opting for universally acceptable, neutral designs, that resembled office space. This might explain the lack of apparent culturally based aesthetic differences in the designs. For students a corporate look could be aspirational, associated with the eagerly anticipated transition into the world of work and adulthood. Yet the design of relatively neutral spaces potentially also implies that internationalisation was seen as requiring abstracting out cultural difference, rather than celebrating individuality and diversity. It could be that the designs of buildings like the information commons, in reflecting business imagery (Spicer and Hancock, 2008), combined with the pressures implied by the need to accommodate large numbers of students, does in fact operate to neutralise cultural diversity visually. The question of whether this is the most appropriate or simply the most practical approach has to be asked. An alternative model of allowing students to own space, as advocated by Bennett and Sagan, is worthy of discussion.

\section{Discussion}

Student designs did reflect many of the priorities identified by Chism for: "flexibility, comfort, sensory stimulation, technology support and decentredness" (2006, p.2.6-7). The design reproduced in figure 2 focuses on comfort and sensory stimulation. The minimal furniture also allows for flexibility. All the designs mentioned technology support, at least access to a computer or wifi network and none actively excluded computers. I3's design with many spaces is truly decentred. The designs did not throw up evidence of different cultural aesthetics, rather they demonstrated many common concerns, e.g. for natural light, for a visually pleasant environment and to control the group's 
visibility. It is striking how far the concerns in the design with light, views and colour mirror the preoccupations of even the youngest school children, as reported in the literature (Ghaziani, 2010; Clark, 2010). The commonality across nationalities is an optimistic finding for on-campus integration.

The analysis has tentatively identified a difference in terms of a greater concern among Chinese students with emotional aspects of learning, especially, a concern to address anxiety and energy levels. UK students seemed to focus on functional requirements. This differs a little from Dunne's (2009) conclusion that anxiety was a pervasive theme of UK students' inter-cultural encounters (she was writing about the Irish context). If confirmed by future research these different focii have implications for teaching practice and policy, in how to think about supporting group working. More allowance has to be given to considerations of recognising and containing emotion within group work before some international students' best efforts towards the task can be mobilised. This supports the ideas developed by Sagan (2008) and Bennett (2005). One is reminded of the way that Turner (2009) found UK students used a focus on task objectives could be used in a punishing way and was built on power dynamics arising from language fluency. If teachers create mixed groups to do assessed work, there is a need to make sure that the groups take time for the emotional aspects of learning and not have a purely task focus. The power differential created by differential competence in language, among other factors, needs to be held in check. The importance of containing anxiety in learning, particularly in contexts where cultural assumptions are potentially challenged is reinforced (Boler and Zemblyas 2003).

Again, there are implications if one accepts the tentative conclusion that the designs were rather conservative and in avoiding culturally and personally significant material, and adopting universal, rather impersonal designs, they reflected an approach to working with others based on neutralising difference. This suggests the need to stress the value of diversity for group work, indeed to reinforce the value of diversity by designing assessment tasks that reward this (mirroring the cultural agility required in the modern workplace). It implies offering up space to celebrate diversity, rather than reproducing the neutral iconography of the office.

Space is an important topic in itself. The spaces offered to students for group work shape how it is done. Equally talking about space and imagining different spaces makes the shaping power of space more visible and once it is more visible empowers learners to make changes. Equally, talking about space is a way into difficult to discuss issues around integration, especially in group work.

\subsection{Reflections on the method}

All the participants showed competence in expressing their ideas through the medium of the model making exercise. Clearly the designs must be understood as implicitly articulating a view of the problems of group work, rather than be taken seriously actual design proposals. It does seem that the method revealed something about underlying feelings and conceptualisations of group work in an internationalised context. The tentativeness of the findings relate to the amount of data, less the method itself. To some degree this confirms the value of using such an indirect approach to avoid the taboos and "aesthetic muteness" that has been identified as a barrier to investigation of internationalisation.

One aspect of the model as a form of data is worth stressing. The objects created in the research were accessible and helped create an on-going discussion in the wider research team, especially when associated with a small amount of explanatory text. Models as artefacts can be seen as working better than text alone to support a highly collaborative research process, on the researchers' side.

Comparing this approach with Clark's (2010) mosaic process, as well as needing more respondents, as a research approach it needed to be complemented with more sources of data. The focus group combined with model making is probably a minimum of data sources. Participant led tours of campus would unlock daily experiences, and might be more successful at exploring the background collaboration between students in learning. Drawing techniques could unlock more unbounded visions of how a university might be designed. The precise design of the model making process needs to be considered. While the organisation of the task in a group seemed productive, the approach does raise issues around whether common themes were the result of copying between participants. From a cognitivist perspective, the exercise would have been more valid if participants had been given precisely the same brief, the same materials and had worked in isolation. Alternatively, the model making could be whole heartedly reconstructed as a collective process, in which the data was the process of discussing possible designs as a group, as much as the final design. This would have been better at surfacing relational aspects of space/group work. For future research both approaches seem potentially valid. The process of the design exercise also has some potential as an enjoyable way to engage students in discussing the organisation of group work. Discussing the outputs with other teaching colleagues could also be a good way to open up questions about the organisation of group work. A further step would 
be to connect such work to the thinking both of estates services, as those managing campus space, and architects, as the designers of new space.

\section{Conclusion}

This paper has been concerned with issues of integration of UK and Chinese students, especially the issues around group work. Exploring these questions through experiences and expectations around space proved to be a stimulating approach. The paper contributes by highlighting the gap in the internationalisation literature around space. Although the students' models did not reveal any differences in underlying cultural aesthetics, the designs did seem to indicate Chinese students were more preoccupied with anxiety and distraction, whereas the UK students' designs were directed to effectively organising the different activities relevant to the group. This finding points to different needs for support. All the models seemed to mask cultural difference rather than celebrate it. This raised questions about how local practices treat diversity. The paper contributes methodologically by confirming the value of visual research methods to open up complex and challenging topics, such as group work and cultural difference. More data collected in different contexts and combined with other types of data could greatly increase our understanding of how to manage the integration of Chinese students.

\section{References}

Baldry, C. (1999). Space: the final frontier, Sociology 33 (3), 535-553. http://dx.doi.org/10.1177/S0038038599000346

Bennett, S. (2005). Righting the balance, Council on Library and Information report. Retrieved 19 January, 2012, from, http://www.clir.org/pubs/reports/pub129/bennett.html

Bland, D. (2010). Drawing on imagination: Primary students' ideal learning environments. In S. Howard (Ed.), AARE 2010 Conference Proceedings, AARE Inc, Melbourne, Australia.

Boler, M. \& Zemblyas, M. (2003). Discomforting truths: the emotional terrain of understanding difference. In P. Tryfonas (Eds.), Pedagogies of Difference: Rethinking Education for Social Change (pp.110-136). New York: Routledge Falmer.

Bragg, S. (2011). "Now it's up to us to interpret it": 'youth voice' and visual methods. In P.Thompson \& J. Sefton-Green (Eds.), Researching creative learning: Methods and issues. London, Routledge, pp.88-103.

Brown, L. (2008). Language and anxiety: an ethnographic study of international postgraduate students, Evaluation and Research in Education, 21 (2) 75-95. http://dx.doi.org/10.1080/09500790802152167

Brown, L. (2009a). An ethnographic study of the friendship patterns of international students in England: An attempt to recreate home through conational interaction, International Journal of Educational Research, 48 (3) 184-193. http://dx.doi.org/10.1016/j.jijer.2009.07.003

Brown, L. (2009b). The transformative power of the international sojourn: An ethnographic study of the international student experience, Annals of tourism research, 36 (3) 502-521. http://dx.doi.org/10.1016/j.annals.2009.03.002

Buckingham, D. (2009). "Creative" visual methods in media research: possibilities, problems and proposals, Media, Culture and Society, 31 (4) 633-652. http://dx.doi.org/10.1177/0163443709335280

Burke, C. \& Grovesnor, I. (2003). The School I'd like. Children and young people's reflection on an Education for the $21^{s t}$ century, London: RoutledgeFalmer.

Carroll, J. (2005). Multicultural groups for discipline-specific tasks. In J. Carroll \& J. Ryan Teaching International Students: improving learning for all (pp.84-91). Abingdon, Routledge.

Chism, N. Van Note. (2006). Challenging traditional assumptions and rethinking learning spaces. In Oblinger, D.G. (Ed.) Learning spaces, Boulder, CO: Educause.

Clark, A. (2010). Transforming children's spaces, Routledge, London.

Clark, R. \& Gieve, S.N. (2006). On the discursive construction of 'The Chinese Learner', Language, culture and curriculum, 19 (1) 54-73. http://dx.doi.org/10.1080/07908310608668754

Cox, A. (2011). Students' Experience of University Space: An Exploratory Study. International Journal of Teaching and Learning in Higher Education, 23(2), 197-207. http://www.isetl.org/ijtlhe/articleView.cfm?id=953

Douglas, D. \& Gifford, R. (2001). Evaluation of the physical classroom by students and professors: a lens model approach, Educational Research 43 (3) 295-309. http://dx.doi.org/10.1080/00131880110081053 
Dunne, C. (2009). Host students' perspectives of intercultural contact in an Irish University, Journal of Studies in International Education, 13 (2) 222-239. http://dx.doi.org/10.1177/1028315308329787

Edwards, V. \& Ran, A. (2006). Meeting the needs of Chinese students in British Higher Education, University of Reading. $\quad 28$ Retrieved October, from, http://www.ncll.org.uk/10_about/50_research/10_research_projects/MeetingTheNeeds.pdf

Edwards, R. \& Usher, R. (2003). Putting space back on the map of learning. In R. Edwards and R.Usher (Eds.), Space, curriculum and learning (pp.1-12). Greenwich, CT: Information Age Publishing.

Ghaziani, R. (2010). School design: Researching children's views, Childhoods today, 4 (1) Retrieved 19 January, 2012, from, http://www.childhoodstoday.org/article.php?id=49

Gu, Q. (2009). Maturity and interculturality: Chinese students' experiences in UK higher education, European Journal of Education, 44 (1) 37-52. http://dx.doi.org/10.1111/j.1465-3435.2008.01369.x

Ippolito, K. (2007). Promoting intercultural learning in a multicultural university: ideals and realities, Teaching in Higher Education, 12 (5) 749-763. http://dx.doi.org/10.1080/13562510701596356

Jamieson, P. (2009). The serious matter of informal learning, Planning for Higher Education 37 (2) 18-25.

Jessop, T., Gubby, L. and Smith, A. (forthcoming). Space frontiers for new pedagogies: a tale of constraints and possibilities, Studies in Higher Education. http://dx.doi.org/10.1080/03075079.2010.503270

Kimmel, K. \& Volet, S. (forthcoming). University students' perceptions and attitudes towards culturally diverse group work: Does context matter? Journal of Studies in International Education. http://dx.doi.org/10.1177/1028315310373833

Leask, B. (2004). Internationalisation outcomes for all students using information and communication technologies (ICTs). Journal of Studies in International Education, 8 (4), pp336-351. http://dx.doi.org/10.1177/1028315303261778

Leask, B. \& Carroll, J. (2011). Moving beyond 'wishing and hoping': internationalisation and student experiences of inclusion and engagement, Higher Education Research and Development, 30 (5) 647-659. http://dx.doi.org/10.1080/07294360.2011.598454

Lewis, M. (2010). The University of Sheffield Library Information Commons: A Case Study, Journal of Library Administration 50 (2) 161-178. http://dx.doi.org/10.1080/01930820903455040

McGregor, J. (2003). Making spaces: teacher workplace topologies, Pedagogy, culture and society. 11 (3) 353-377. http://dx.doi.org/10.1080/14681360300200179

McGregor, J. (2004). Spatiality and the place of the material in schools, Pedagogy, culture and society, 12 (3) 347-372. http://dx.doi.org/10.1080/14681360400200207

Marmot Associates. (2006). Spaces for learning: a review of learning spaces in further and higher education. Retrieved 19 January, 2012, from, http://www.jiscinfonet.ac.uk/Resources/external-resources/sfc-spaces-for-learning Morey, A. I. (2000). "Changing higher education curricula for a global and multicultural world", Higher education in Europe, 25 (1) 25-39. http://dx.doi.org/10.1080/03797720050002170

Peacock, N. \& Harrison, N. (2009). "It's so much easier to go with what's easy": Mindfulness and the discourse between home and international students in the United Kingdom, Journal of Studies in International Education, 13 (4) 487-508. http://dx.doi.org/10.1177/1028315308319508

Peacock, N. \& Harrison, N. (2010). Cultural distance, mindfulness and passive xenophobia: using Integrated Threat theory to explore home higher education students' perspective on "internationalisation at home British Educational Research Journal, 36 (6) 877-902. http://dx.doi.org/10.1080/01411920903191047

Philo, G. (2007). Cultural transfer: The impact of direct experience on evaluations of British and Chinese societies. British Council.

Prosser, J. \& Loxley, A. (2008). Introducing visual methods, ESRC National Centre for Research Methods Review Paper.

Sagan, O. (2008). Playgrounds, studios and hiding places: emotional exchange in creative learning spaces, Art, Design and Communication in Higher Education 16 (3) 173-186. http://dx.doi.org/10.1386/adch.6.3.173_1

Simpson, R., Sturges, J. \& Weight, P. (2009). Transient, unsettling and creative space: Experiences of liminality 
through the accounts of Chinese students on a UK-based MBA, Management Learning, 41 (1) 53-70. http://dx.doi.org/10.1177/1350507609350830

Skelton, A. (2005). Internationalization and intercultural learning, In A. Skelton, A. (Eds.), Understanding teaching excellence in Higher Education (pp.102-115). Oxford: Routledge.

Spencer, M.E. (2006). Evolving a new model: The information commons, Reference Service Review 34 (2) 242-247. http://dx.doi.org/10.1108/00907320610669470

Spicer, A. \& Hancock, P. (2008). Creating an image of business in the 'new library', paper given $1^{\text {st }}$ workshop on imagining business, Oxford.

Summers, M. \& Volet, S. (2008). Students' attitudes towards culturally mixed groups on international campuses: impact of participation in diverse and non-diverse groups, Studies in Higher Education, 33 (4) 357-370. http://dx.doi.org/10.1080/03075070802211430

Tani, M. (2005). Quiet, but only in class: reviewing the in-class participation of Asian students, HERDSA conference, Retrieved 19 January, 2012, from, http://conference.herdsa.org.au/2005/pdf/non_refereed/030.pdf

Taylor, S.S. (2002). Overcoming aesthetic muteness: Researching organizational members' aesthetic experience, Human Relations, 55 (7) 821-840. http://dx.doi.org/10.1177/0018726702055007542

Taylor, S. \& Spicer, A. (2007). Time for space: A narrative review of research on organisational spaces, International Journal of Management Reviews, 9 (4) 325-346. http://dx.doi.org/10.1111/j.1468-2370.2007.00214.x

Temple, P. (2007). Learning spaces for the $21^{\text {st }}$ century. Retrieved 19 January, 2012, from, http://www.heacademy.ac.uk/assets/York/documents/ourwork/research/Learning\%20spaces\%20for\%20the\%2021st\% 20century.pdf

Thomson, P. (2007). Working with in/visible geography of school exclusion, In K.N. Gulson \& C. Symes (Ed.s), Spatial theories of Education (pp.111-130). New York: Routledge.

Tian, M. \& Lowe, J. (2009). Existentialist internationalisation and the Chinese student experience in English universities, Compare: A journal of Comparative and International Education, 39 (5) 659-676. http://dx.doi.org/10.1080/03057920903125693

Turner, Y. (2009). "Knowing me, knowing, you," is there nothing we can do? Journal of Studies in International Education, 13 (2) 240-255. http://dx.doi.org/10.1177/1028315308329789

Usher, R. (2002). Putting space back on the map: globalisation, place and identity, Educational Philosophy and Theory 34 (1) 41-55. http://dx.doi.org/10.1111/j.1469-5812.2002.tb00285.x

UKCISA (2011). International students in UK higher education: key statistics, Retrieved 19 January, 2012, from, http://www.ukcisa.org.uk/about/statistics_he.php

UKCOSA (2004). International students in UK universities and colleges: broadening our horizons: report of the UKCOSA survey. $\quad$ Retrieved 19 January, 2012, from, http://www.ukcisa.org.uk/files/pdf/about/reports/BOHsummary.pdf

Volet, S.E. \& Ang, G. (1998). Culturally mixed groups on international campuses: An opportunity for inter-cultural learning, Higher Education Research \& Development, 17 (1) 5-23. http://dx.doi.org/10.1080/0729436980170101

Zhou, Y. \& Todman, J. (2009). Patterns of adaptation of Chinese postgraduate students in the United Kingdom, Journal of Studies in International Education, 13 (4) 467-486. http://dx.doi.org/10.1177/1028315308317937 


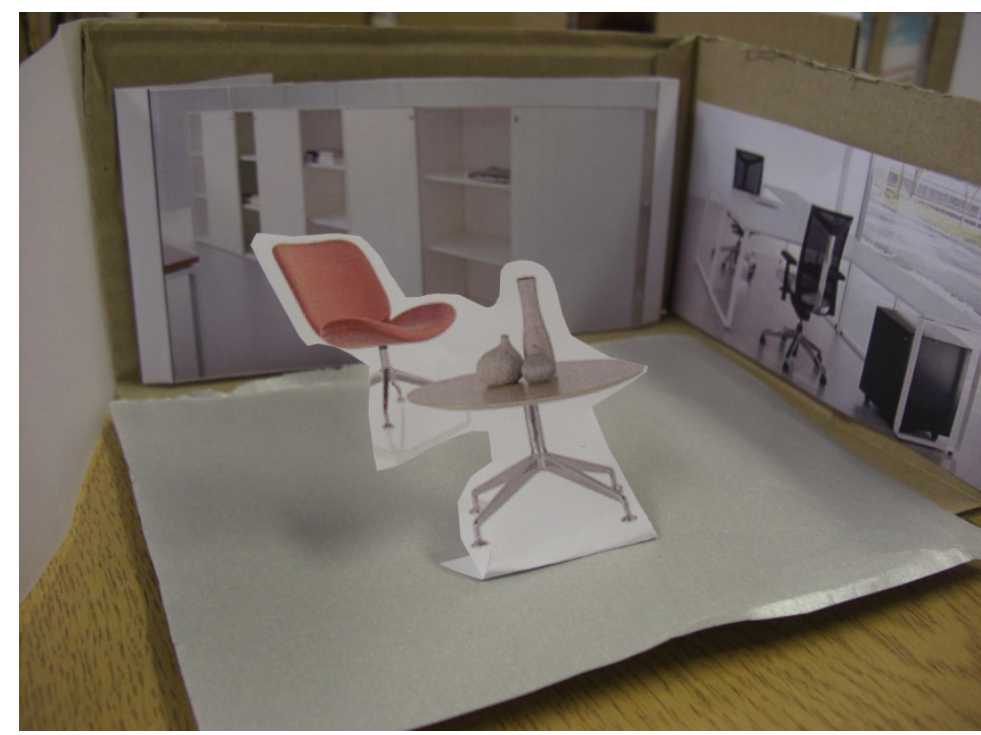

Figure 1. I1's design based on "simple" colours and few distractions

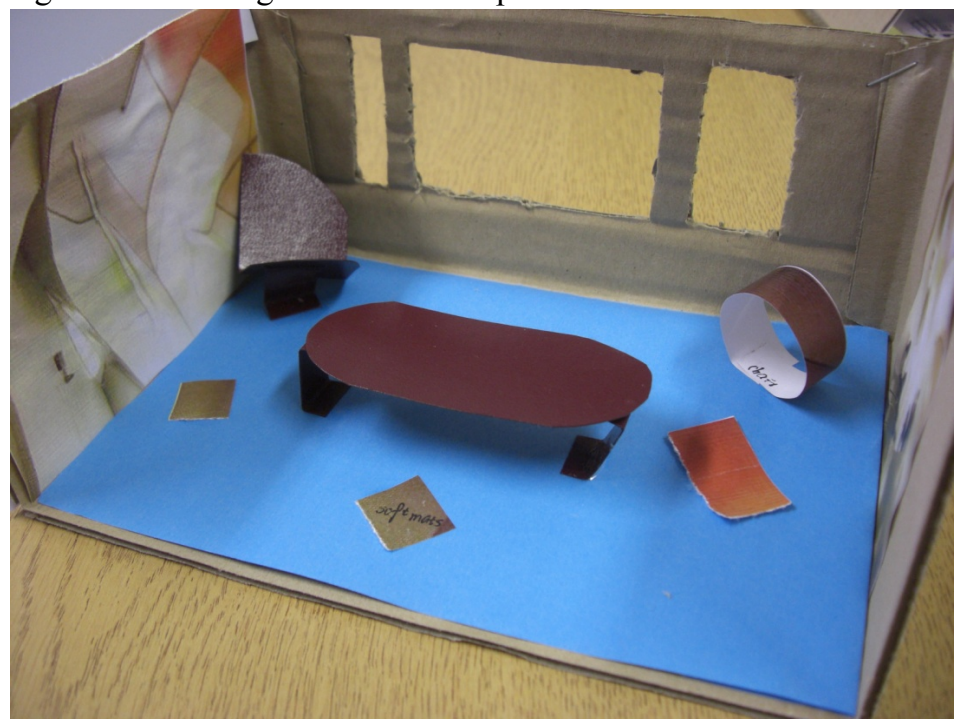

Figure 2. I2's design with sky blue floor, soft mats and a special chair

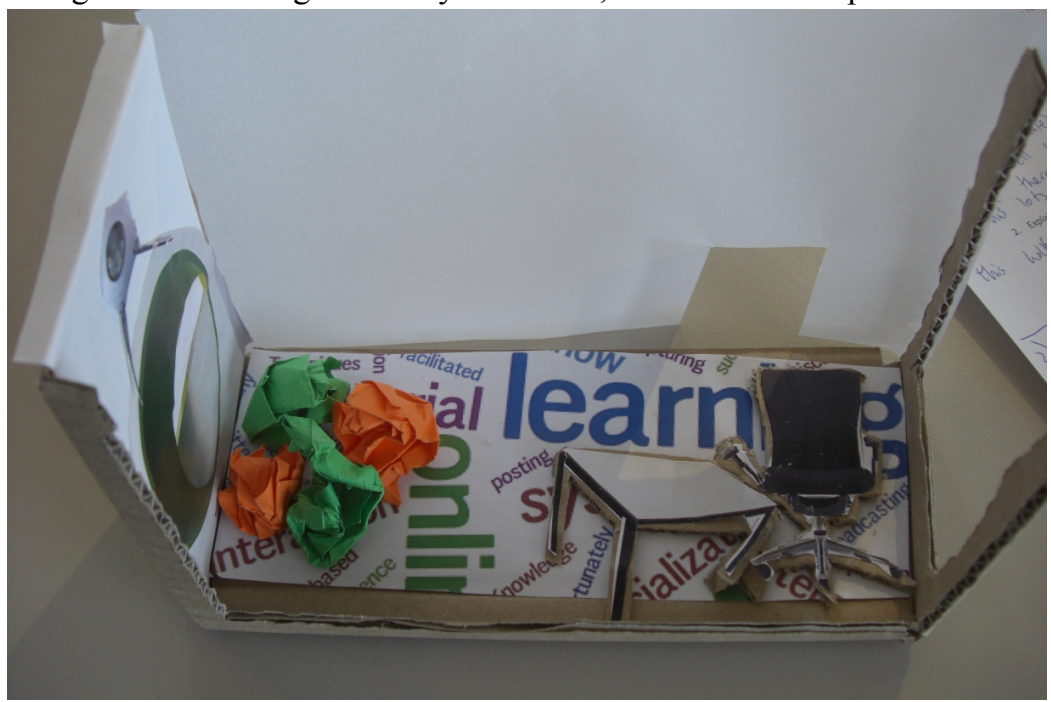

Figure 3. I4's design with two walls that are windows and one translucent wall 